\title{
Crystallization and Melting Behavior of Biodegradable Poly(L-lactic acid)/Talc Composites
}

\author{
YAN-HUA CAI \\ School of Materials and Chemical Engineering, ChongQing University of Arts and Sciences, \\ 402160, Yongchuan, ChongQing, P.R. China \\ caiyh651@yahoo.com.cn
}

Received 19 November 2011; Accepted 15 January 2012

\begin{abstract}
Crystallization and melting behavior of Poly(L-lactic acid)(PLLA)/Talc composites with different talc content were investigated in detail. The addition of talc can increase the overall crystallization rate of PLLA, 5\%talc makes the melt-crystallization peak temperature of PLLA increase from $96.28{ }^{\circ} \mathrm{C}$ to $105.22{ }^{\circ} \mathrm{C}$, and the crystallization enthalpy increases from $1.379 \mathrm{~J} \cdot \mathrm{g}^{-1}$ to $28.99 \mathrm{~J} \bullet \mathrm{g}^{-1}$. The melting behavior of PLLA $/ 5 \%$ talc composites at a different heating rate during non-isothermal crystallization at different cooling rate shows that heating rate can affect the melting behavior of PLLA, with increasing of heating rate, the double melting peak degenerates to single melting peak. Melting behavior after isothermal crystallization and after cold isothermal crystallization and hot isothermal crystallization indicates that the double-melting peak of PLLA $/ 5 \%$ talc composites results from meltingrecrystallization.
\end{abstract}

Key Words: Poly(L-lactic acid); Talc; Crystallization; Melting behavior; Composites.

\section{Introduction}

Poly(L-lactic acid)(PLLA) is the most important biodegradable polymers, and has been applied in more and more industry due to its lower energy consumption, biopolymer and non-toxic to the environment ${ }^{[1-3]}$. However, there exist many weakness such as slow crystallization rate, low crystalline degree and poor heat resistance, etc. Talc is often chosen as nucleating agent of PLLA, it was shown that talc nucleates the crystallization of polymers through an epitaxial mechanism ${ }^{[4]}$. The crystallization behavior and the morphology of poly (L-lactide-co-meso-lactide) and poly (L-lactide-co-meso-lactide)/Talc composites shows that strong increase in nucleation density with addition of talc was found in poly (L-lactideco-meso-lactide $)^{[5]}$. And the overall crystallization rate of PLLA increased with increasing content of talc ${ }^{[6]}$. The addition of talc not only affects the crystallization behavior of PLLA in a significant manner but also has a strong effect on melting behavior.Double melting peaks are often reported in PLLA non-isothermal crystallization process from the melt ${ }^{[7]}$. And there exist two mechanism of forming of double melting peaks ${ }^{[7]}$, including the meltrecrystallization mechanism and the melting of two populations of lamellae. 
As to PLLA/talc composites, the melting behavior of PLLA/talc composites little is reported by literature. In this paper, crystallization and melting behavior of biodegradable Poly(L-lactic acid)/talc composites with different talc content were investigated in detail, and the mechanism of forming of double melting peaks was discussed.

\section{Experimental Section}

\section{Materials}

Poly(L-lactic acid) (2002D) was purchased from Nature Works LLC, USA. The talc was purchased from shanghai yuejiang titanium chemical manufacturer co., LTD.

\section{Preparation of PLLA/Talc Composites}

Blending of PLLA and talc was performed on a counter-rotating mixer, and the preparation process of PLLA/talc composites has described in our previous paper ${ }^{[8]}$.

\section{Characterization}

Differential Scanning Calorimeter (DSC): The non-isothermal crystallization behavior of PLLA/talc composites was measured by DSC Q2000 (TA Instrumrnts-Waters LLC, USA). The temperature and heat flow at different heating rate were calibrated using an indium standard. The sample was heated to $190^{\circ} \mathrm{C}$ and maintained at that temperature for $5 \mathrm{~min}$ to make sure that the polymer crystals were melted completely. Then the samples were cooled from the melt state to $20^{\circ} \mathrm{C}$ at different cooling rate. The melting behavior with different condition was measured by DSC Q2000 instrument.

\section{Results and discussion}

\section{Non-Isothermal Crystallization of PLLA/Talc Composites}

Figure 1 shows the DSC curves of non-isothermal crystallization from melt of PLLA/talc composites with different talc content. As seen in figure 1, upon cooling rate at $1{ }^{\circ} \mathrm{C} / \mathrm{min}$, the crystallization peak of PLLA can almost not be detected, which shows that the crystallization of neat PLLA is very slow. With addition of talc, crystallization peak appears in the DSC cooling curve. Compared to the neat PLLA, talc addition leads to the shift of crystallization peak to high temperature indicating the increase of crystallization temperature, and the crystallization peak shifts to higher temperature with increasing of talc content. On the other hand, crystallization peak for PLLA containing talc becomes much sharper in the cooling process, this result shows that talc can serve as a nucleating agent for the crystallization, and increase the overall crystallization rate of PLLA ${ }^{[8] .}$ Compared to the other talc content, 5\% talc makes the crystallization rate become fastest. As seen in Table 1, compared to the neat PLLA, with the addition of 5\%talc, the crystallization temperature $\left(T_{o}\right)$ increases from $105.88{ }^{\circ} \mathrm{C}$ to $109.91^{\circ} \mathrm{C}$, melt-crystallization peak temperature $\left(T_{m o}\right)$ increases from $96.28{ }^{\circ} \mathrm{C}$ to $105.22{ }^{\circ} \mathrm{C}$, and the crystallization enthalpy $\left(\Delta H_{c}\right)$ increases from $1.379 \mathrm{~J} \cdot \mathrm{g}^{-1}$ to $28.99 \mathrm{~J} \cdot \mathrm{g}^{-1}$. However, there existed the most crystallization enthalpy of PLLA/talc composites with the addition of $3 \%$ talc. 


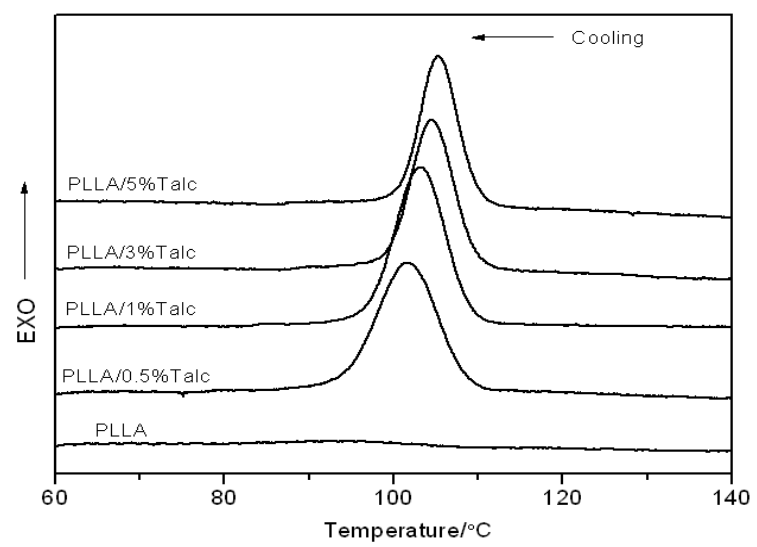

Figure 1. DSC curves of non-isothermal crystallization from melt of PLLA/Talc composites with different talc content.

Table 1. DSC date of PLLA/talc composites crystallized from melt at cooling of $1{ }^{\circ} \mathrm{C} / \mathrm{min}$.

\begin{tabular}{cccc}
\hline Sample & $T_{o} /{ }^{\circ} \mathrm{C}$ & $T_{m o} /{ }^{\circ} \mathrm{C}$ & $\Delta H_{c} / \mathrm{J} \cdot \mathrm{g}^{-1}$ \\
\hline PLLA & 105.88 & 96.28 & 1.379 \\
PLLA/0.5\%talc & 108.56 & 101.85 & 28.52 \\
PLLA/1\%talc & 108.90 & 103.24 & 28.68 \\
PLLA/3\%talc & 109.67 & 104.56 & 29.54 \\
PLLA/5\%talc & 109.91 & 105.22 & 28.99 \\
\hline
\end{tabular}

Melting Behavior of PLLA/5\% Talc at Different Heating Rate after Non-isothermal Crystallization at Different Cooling Rate

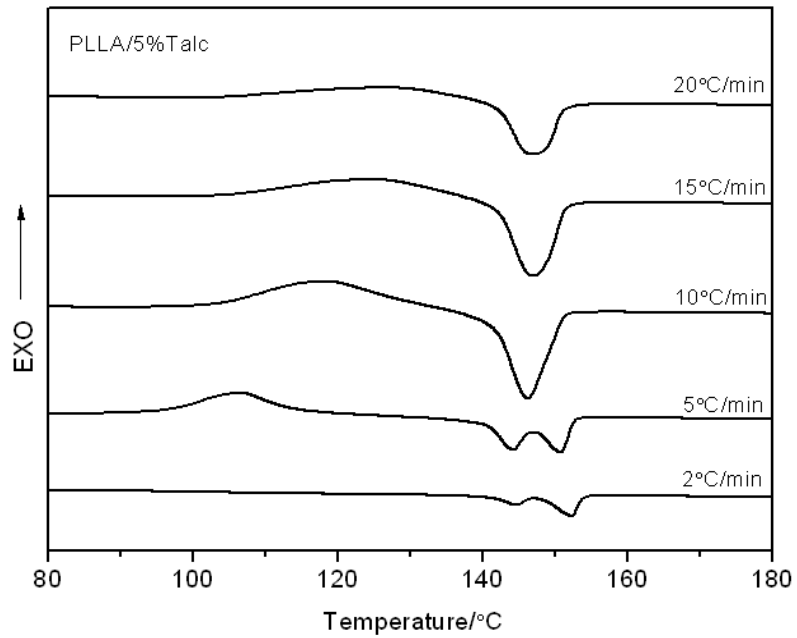

Figure 2. Melting behavior of PLLA/5\%talc composites at a different heating rate during non-isothermal crystallization at different cooling rate. 
Figure 2 shows the melting behavior of PLLA/5\%talc composites at a different heating rate during non-isothermal crystallization at different cooling rate. With increasing of heating rate, the double melting peak degenerates to single melting peak. It is clear that the high-temperature melting peak of PLLA/5\%talc composites shifts to low-temperature with increasing of heating rate, the reason is that the increasing of heating rate makes the crystallization of PLLA to be incomplete, and the prefect of spherulite becomes worse. However, the low-temperature melting peak shifts to high-temperature. Meantime, there exist obvious second crystallization process with increasing of heating rate, this is due to incomplete of crystallization of PLLA with increasing of heating rate. According to the other literature ${ }^{[9]}$, The double-melting behavior of PLLA assigns to melting-recrystallization, the low-temperature melting peak is attributed to the primary crystallites formed at $T_{c}$, and hightemperature melting peak reflect the relatively prefect lamella stacks resulted from recrystallization during the heating scan.

\section{Melting Behavior at Different Heating Rate after Isothermal Crystallization for $1 \mathrm{~h}$ at $10^{\circ} \mathrm{C}$}

Figure 3 shows the DSC of PLLA $/ 5 \%$ talc composites at different heating rate during isothermal crystallization for $1 \mathrm{~h}$ at $100^{\circ} \mathrm{C}$. With increasing of heating rate, the double melting peak degenerate to single melting peak, and the high-temperature melting peak existed in the form of pulse. And the low-temperature melting peak of PLLA $/ 5 \%$ talc composites does not shift with increasing of heating rate. However, the high-temperature melting peak shifts to low themperature with increasing of heating rate, the reason may be that the increasing of heating rate makes the degree of recrystallization of imperfect crystal decrease, which confirmed that double-melting peak of PLLA $/ 5 \%$ talc composites result from melting-recrystallization.

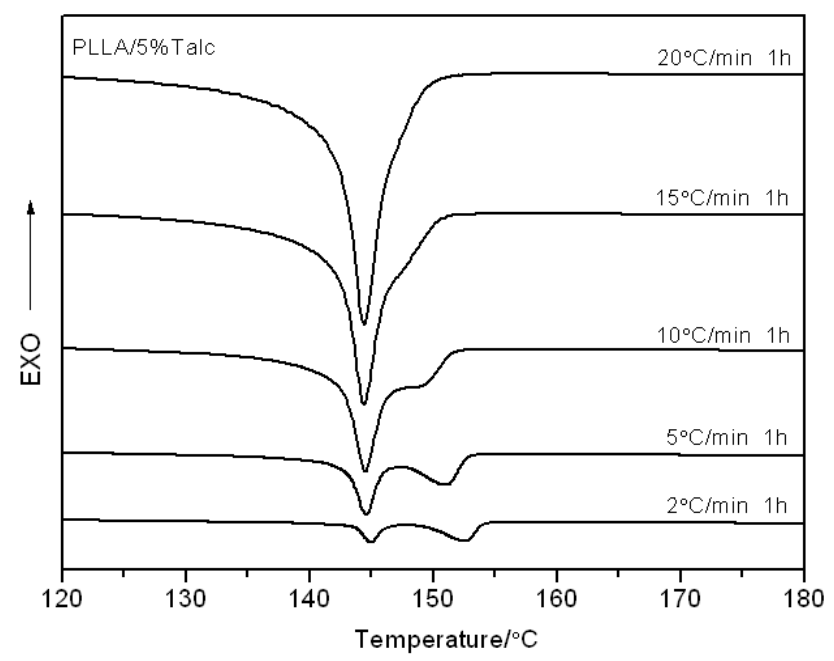

Figure 3. Melting behavior of PLLA $/ 5 \%$ talc composites at different heating rate during isothermal crystallization for $1 \mathrm{~h}$ at $100^{\circ} \mathrm{C}$.

\section{Melting Behavior of PLLA/5\% Talc Composites after Cold Isothermal Crystallization and Hot Isothermal Crystallization}

Figure 4 shows the melting behavior of PLLA/5\%talc composites after cold isothermal crystallization and hot isothermal crystallization. As seen in Figure.4, the melting temperature of PLLA $/ 5 \%$ talc increases with increasing of isothermal temperature, the reason 
is that high crystallization temperature makes the crystal of PLLA $/ 5 \%$ talc composites to be more prefect, and the spherulite is bigger. And the melting temprature of PLLA $/ 5 \%$ talc through hot isothermal crystallization is higher than that through cold isothermal crystallization, which indicates that cold isothermal crystallization process can improve the crystallization of PLLA, but the prefect of spherulite become worse.

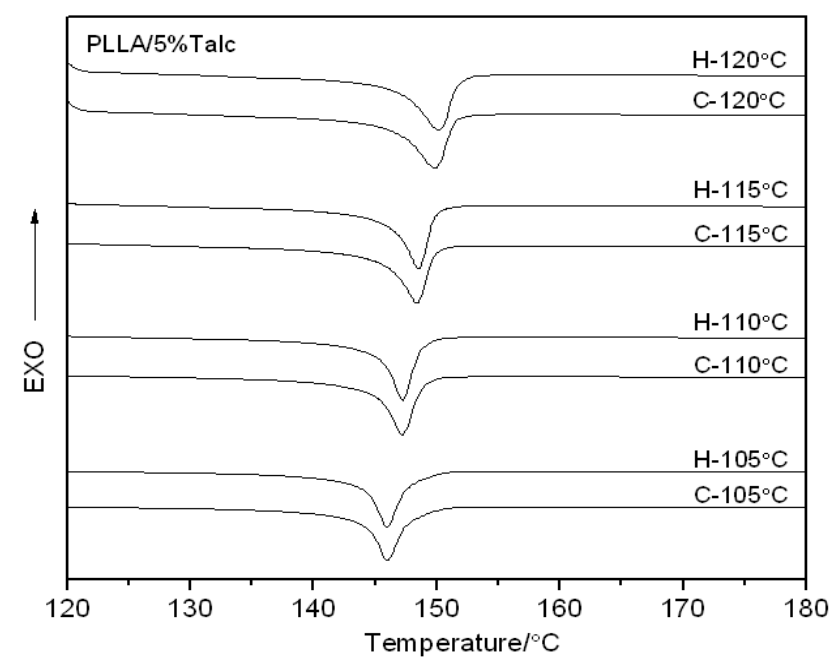

Figure 4. Melting behavior of PLLA/5\%talc composites after cold isothermal crystallization and hot isothermal crystallization.

\section{Conclusion}

Crystallization and melting behavior of PLLA/Talc composites with different talc content were investigated in detail. The addition of $5 \%$ talc makes the melt-crystallization peak temperature of PLLA increase from $96.28^{\circ} \mathrm{C}$ to $105.22^{\circ} \mathrm{C}$, and the crystallization enthalpy increases from $1.379 \mathrm{~J} \mathrm{~g}^{-1}$ to $28.99 \mathrm{~J} \bullet \mathrm{g}^{-1}$. The melting behavior of PLLA $/ 5 \%$ talc composites shows that heating rate can affect the melting behavior of PLLA, with increasing of heating rate, the double melting peak degenerates to single melting peak. And the double-melting peak of PLLA $/ 5 \%$ talc composites results from melting-recrystallization.

\section{References}

1. Pengju Pan, Zhichao Liang, Bo Zhu, Tungalag Dong, and Yoshio Inoue. Blending Effects

on Polymorphic Crystallization of Poly(L-lactide)[J], Macromolecules, 2009, 42: 3374-3380.

2. Zhiyuan Jia, Kunyu Zhang, Juanjuan Tan, Changyu Han, Lisong Dong, Yuming Yang. Crystallization Behavior and Mechanical Properties of Crosslinked Plasticized Poly(L-lactic acid)[J], Journal of Applied Polymer Science, 2009, 111: 1530-1539.

3. Hu J, Sun X, Ma H Y, Xie C Q, Chen Y. Eugene. Porous nanofibrous PLLA scaffolds for

vascular tissue engineering [J], Biomaterials, 2010, 31(31): 7971-7977.

4. Haubruge HG, Daussin R, Jonas AM, and Legras R, Epitaxial Nucleation of

Poly(ethylene terephthalate) by Talc: Structure at the Lattice and Lamellar Scales[J],

5. Macromolecules, 2002, 36: 4452-4456. 
6. Kolstad JJ, Crystallization Kinetics of Poly(i-lactide-co-meso-lactide)[J], Journal of Applied Polymer Science, 1996, 62: 1079-1091.

7. Ke TY, and Sun XZ, Melting Behavior and Crystallization Kinetics of. Starch and Poly(lactic acid) Composites[J], Journal of Applied Polymer Science, 2003, 89: 1203-1210.

8. Zhizhong Su, Qiuying Li, Yongjun Liu, Guohua Hu, Chifei Wu. Multiple Melting. Behavior of Poly(lactic acid) Filled with Modified Carbon Black[J], Journal of Polymer

Science: Part B: Polymer Physics, 2009, 47:1971-1980.

9. YanHua Cai, JingBo Yin, YinQing Fan, et al. Crystallization Behavior of Biodegradable

Poly(L-lactic acid) Filled with a Powerful Nucleating Agent-N, N'-Bis(benzoyl) Suberic

Acid Dihydrazide [J], Journal of Applied Polymer Science, 2011, 121(3): 1408-1416.

10. Munehisa Yasuniwa, Shinsuke Tsubakihara, Youhei Sugimoto, Chitoshi Nakafuku.

Thermal analysis of the double-melting behavior of poly(L-lactic acid) [J], Journal of Polymer Science Part B: Polymer Physics, 2004, 42(1): 25-32. 


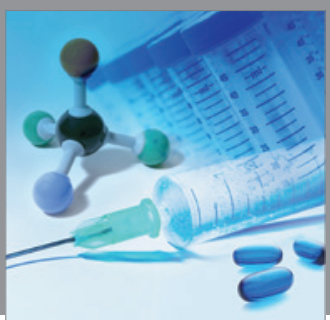

International Journal of

Medicinal Chemistry

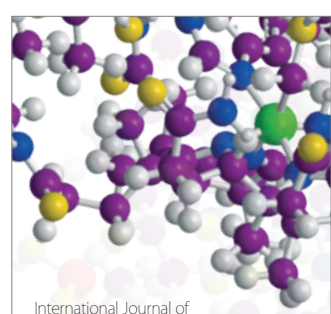

Carbohydrate Chemistry

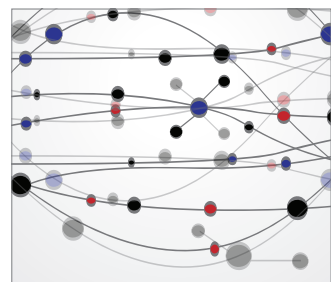

The Scientific World Journal
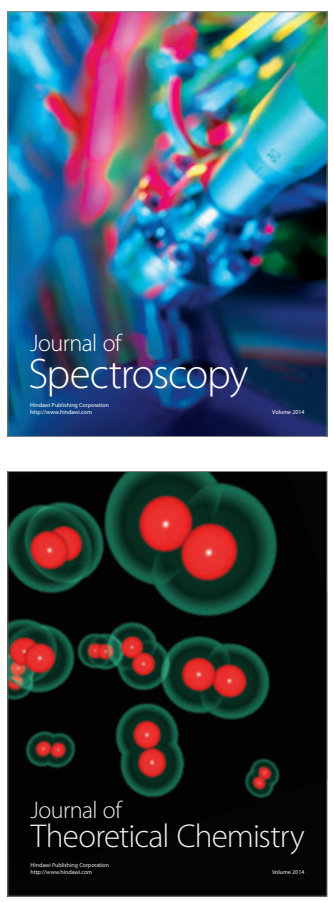
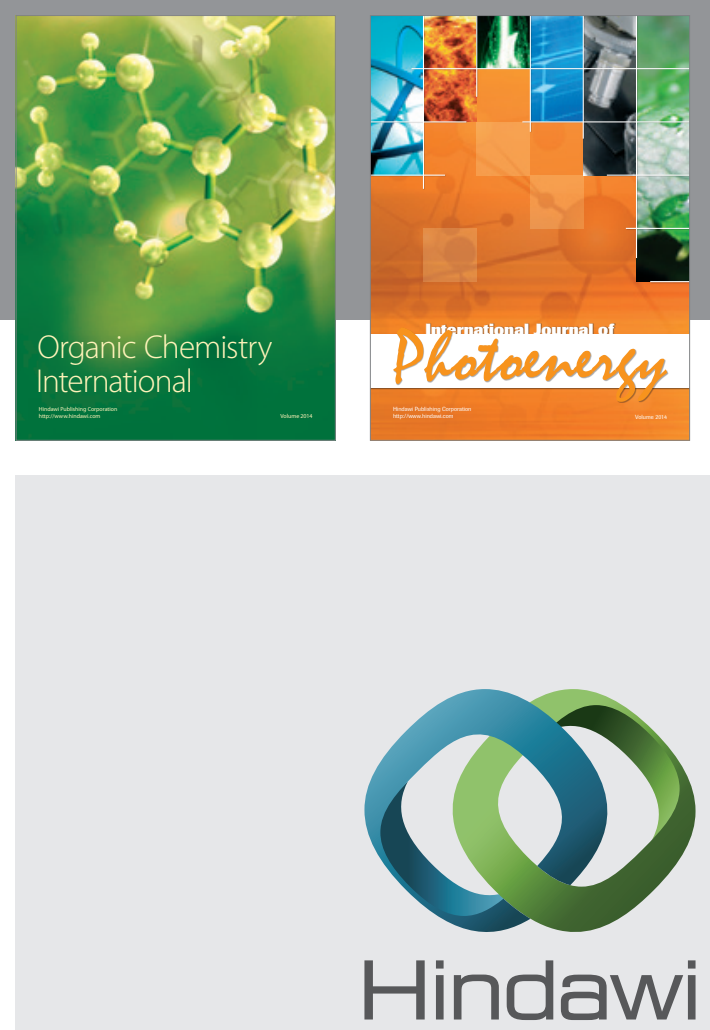

Submit your manuscripts at

http://www.hindawi.com
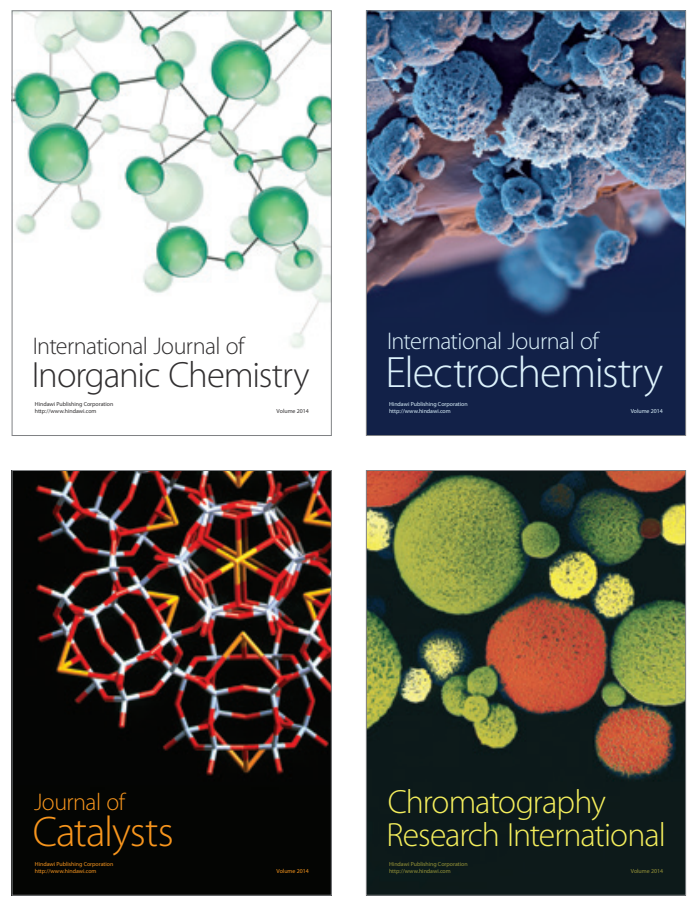
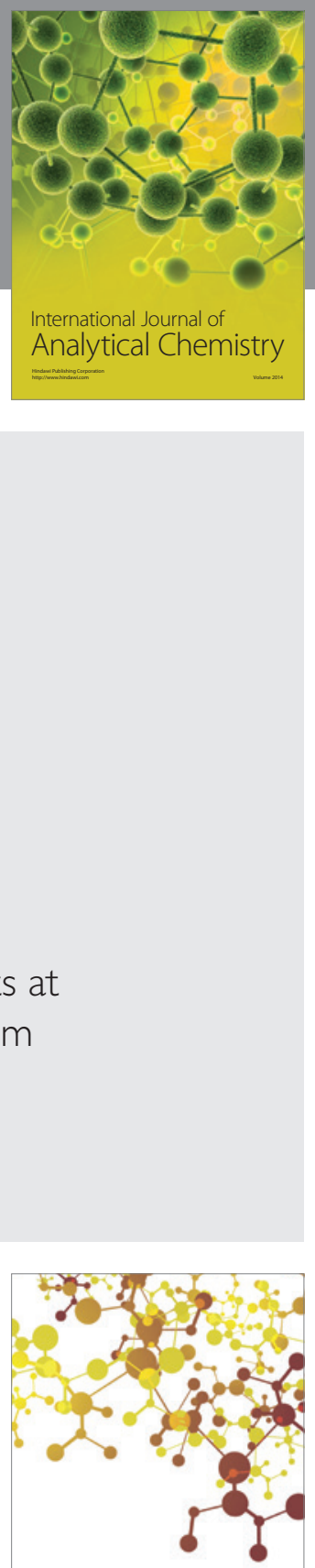

Journal of

Applied Chemistry
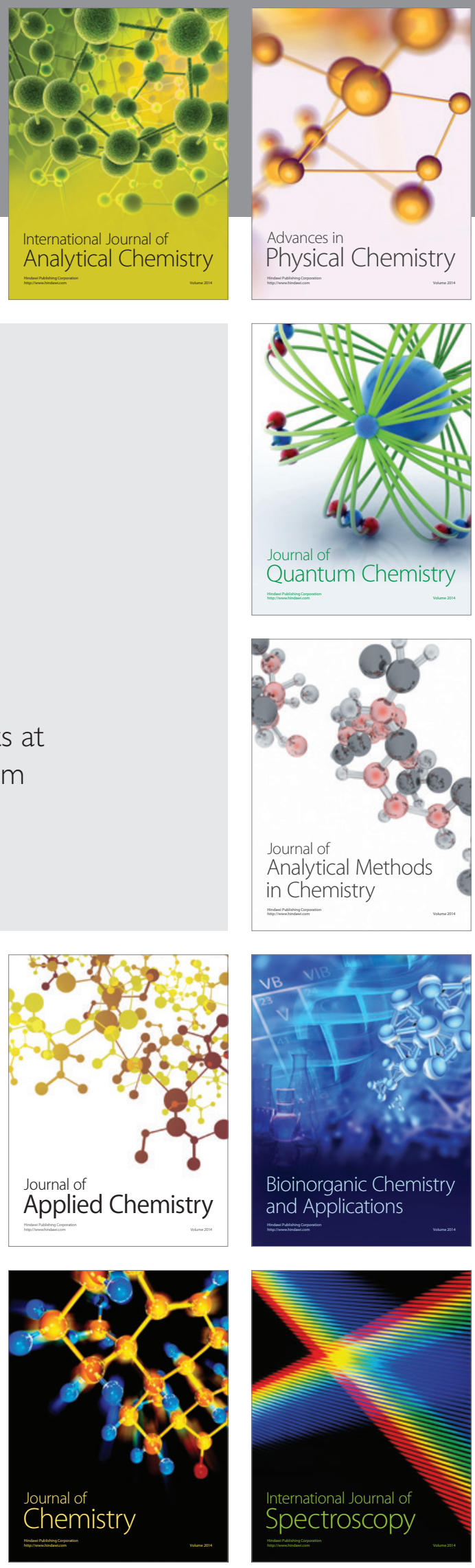